of all the periodicals to which we had subscribed since 1980. Holdings and call numbers were included for each title. For each index we noted those titles on our list which were covered by the index. The lists provided in the indexes themselves were supplemented with information taken from our serials control system (in this case SC350) which allowed us to search and display the 510 field of the MARC records for our serials. This information was displayed in a simple, single-line format in alphabetical order by periodical title.

This project took some time, but was made considerably simpler by having some of this information already on disk. The rest was added over the course of several months. The products have been some 11 index-specific lists that are kept on the consulting table beside the appropriate index. Rather than check citations against a large alphabet of titles, users can check a short list that pertains to just the index they are using. This is particularly useful at the CD indexes. The WilsonDisc indexes we have only extend back to the early 1980s, so the lists we produce are completely accurate as to our holdings of the journals indexed. Maintaining the lists has proven to be quite easy. Both staff and students agree that the time to produce the lists was well spent.

The interesting development is that our requests for interlibrary loans have decreased quite significantly for the twelve months since these lists were produced. This may be coincidental, but other libraries I have contacted do not report this trend. We may be able to attribute this decrease in more effective use of our own collection. The CD indexes make it easy to search multiple years of an index, and the lists we have produced enable users to quickly check which ones are here. Circulation of bound and unbound periodicals the past year showed a $15 \%$ increase compared to the average of the previous 4 years, and was $26 \%$ above the immediately prior year.

To see interlibrary loan going down at the same time that local circulation is on the rise does raise some questions. Users may be relying on articles several years old instead of requesting newer articles from journals we don't have. For most undergraduate research and paper-writing this is probably satisfactory. It just might be that some fairly simple efforts to improve access have contributed to this result.

\title{
Section funding discussion
}

\section{By Helen H. Spalding}

\author{
Associate Director of Libraries \\ University of Missouri-Kansas City
}

\begin{abstract}
ACRL's Budget and Finance Committee has been reviewing how ACRL sections are funded within the overall divisional budget and is now asking for your input. Nothing is inherently wrong with how sections are funded within the division, but with the current level of section participation, it may be a good time to look at current practice, inform the members, and document the funding structure.
\end{abstract}

In an effort to examine section funding strategies and formulate recommendations for keeping the current practice- or for trying one that may be more responsive to the priorities and needs of membership - the Budget and Finance Committee is inviting all members to attend an open hearing on section funding on Sunday, January 13, 1991, at the ALA Midwinter Meeting, from 8:00 p.m. to 10:00 p.m. (location to be announced). Your reaction to this article and feedback at the open hearing is crucial to the Committee's ability to determine if change is warranted, and if so, how it can be done in the best interests of the members.

Divisional dues are the only source of funds the Budget and Finance Committee has to support membership services, including Board support; statistics; advisory services; standards distribution; awards; committees; sections; chapters and discussion groups. When sections generate new activities (newsletters, for example) that require financial support, or when new sections are formed, their funding must come from this pool of membership dues. Unless membership dues are raised to cover new activities, section budgets must be weighed against other member activities.

Traditionally, the sixteen ACRL sections submit their annual budget requests, with justification based upon the Strategic Plan, by December 1 each year. Based upon the section's initiative, the current division budget, and the projected division budget, the Budget and Finance Committee rec- 
ommends a certain level of funding to the Board. There is no minimum entitlement that each section automatically receives.

Any section that requests a newsletter is funded within the policy limitation of either two issues a year with 8 pages each, or one annual issue with up to 16 pages. Funding for additional pages must be supported by the ACRL Publications Committee and recommended by the Budget and Finance Committee (12 sections currently distribute newsletters).

Any section that requests an orientation manual is generally funded for one, with distribution to section officers and committee members.

There is no question that the sections represent diverse needs and activities. A section may be formed when a group of 25 or more members, representing a field of activity distinct from those of existing sections and within the scope of ACRL's field of interest, receives Board approval to do so. There is no mandate that a section have a budget, or plan activities requiring a budget. The oldest and largest section is the University Libraries Section, formed in 1937, now with over 6,000 members. Its budget is modest relative to smaller sections. The newest sections are the Afro-American Studies Librarian Section (1989), and the Extended Campus Library Services Section (1990).

In recognition of the diversity of interests and activities among the sections, ACRL has not funded sections on a strict per capita basis. Although such a distribution would be easier to understand and administer, it would result in small but active sections that are unable to pursue worthwhile services to members, while larger sections with objectives that require less funding would be forced to generate programs to spend their larger budgets. Another consideration is that support for new sections must be carved out of funds that more established sections are accustomed to receiving unless membership dues are raised to accommodate them. How to respond to exciting new section proposals is an ongoing problem, especially when some other membership services must be compromised to address them.

The Budget and inance Committee is including the membership early in its examination of section funding. The way sections are now funded will not necessarily be changed. The Committee is looking at several alternative funding models, but they need your perspective, especially if you are active in a section. Contact: Leslie Manning, Chair, ACRL Budget and Finance Committee, University of Colorado at Colorado Springs Library, 1420 Austin Bluffs Parkway, P.O. Box 7150, Colorado Springs, CO 80933-7150. Join the member dialogue at the open hearing on section funding, Sunday, January 13, 1991, 8:00-10:00 p.m.

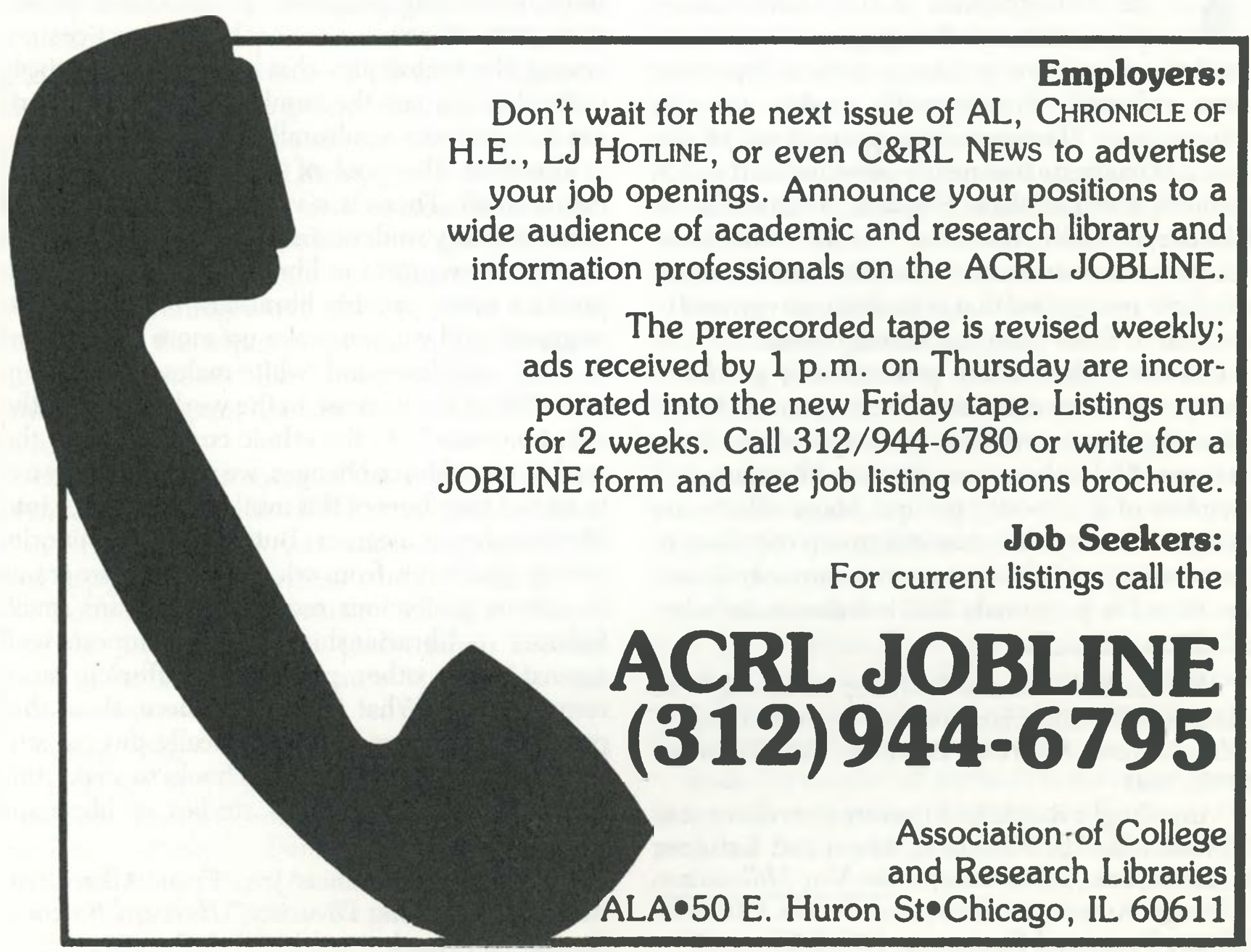

